\title{
Çocuk Edebiyatı Üzerine Yapılmış Lisansüstü Çalışmaların İçerik Analizi (2011-2018 Yillari)
}

\author{
DOI: 10.26466/opus.510809 \\ * \\ Elif Emine Balta \\ * Dr, Bağımsız Araştırmacı, Ankara/ Türkiye \\ E-Posta: elifkucuk@hotmail.com \\ ORCID:0000-0001-8958-4628
}

\begin{abstract}
Öz
Türkiye'de çocuk edebiyatının öneminin fark edilmesiyle çocuklara yönelik eserler gelişmiş, sayıca artmış bununla birlikte akademik düzlemde de çeşitli yönlerden incelemeye tabi tutulmuştur. Bu araştırmada Türkiye'de çocuk edebiyatı hakkında yapılmış olan lisansüstü çalışmaların yıl, üniversite, enstitü, bilim dalı, yazıldı̆̆g dil, konu, konu alınan yazar/şair/çocuk edebiyatçısı, incelenen tema, kullanılan yöntem, veri kaynakları, veri analiz teknikleri bağlamında incelenmesi amaçlanmıştır. Araştırma 20112018 yılları ile sınırlandırılmıştır. Yapılmış lisansüstü çalışmaların Türk çocuk edebiyatı ve eserlerini kapsaması noktasında sinırlandırmaya gidilmemiş, YÖK'e kayıtlı olan "çocuk edebiyatı" odaklı tezler dikkate alınmış ve araştırmaya 278 tez dâhil edilmiştir. Derlenen tezler içerik analizine uygun olarak çalışmanın amacı çerçevesinde kodlanmış, kodlanan tezler kategorik verilere dönüştürülmüş elde edilen sonuçlar grafik, frekans ve yüzde tabloları olarak betimsel olarak gösterilmiştir. Analiz bulgularından bazıları çocuk edebiyatı odakl lisansüstü tezlerinin 2017'ye kadar artıs gösterdiğ i, büyük oranda eğitim

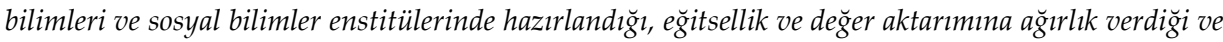
yöntem olarak nitel yöntemin tercih edildiğidir. Ayrıca ulaşılan sonuçlar bă̆lamında gelecek araştırmalar için öneriler sunulmuştur.
\end{abstract}

Anahtar Kelimeler: Çocuk edebiyatı, içerik analizi, yüksek lisans tezi, doktora tezi 


\title{
A Content Analysis Post-Graduate Studies in Turkey About Children's Literature (2011-2018 Period)
}

\begin{abstract}
By realizing the importance of children's literature in Turkey, works for children have been developed, increased in number and examined in various aspects of the academic plane. In this study, it is aimed to examine the post-graduate studies about children's literature in Turkey in the context of years, university, institute, field, language, subject, author/poet/teacher of children's literature of subject, method, data sources, data analysis techniques. The thesis focused on "children's literature" which are registered to the Turkish Higher Education Council (YÖK) are taken into consideration and 278 thesis are included in the study. The compiled theses are coded within the framework of the purpose of the study in accordance with the content analysis. These coded theses are transformed into categorical data and the results are shown as graphs, descriptive tables of frequencies and percentages. Some of the analysis findings are that thesis focused on "children's literature" showed an increase from 2013 to 2017; high ratio is prepared in educational science institutes, concentrate on educational message and value transfer, and the qualitative method is preferred in studies. Proposals for future researches are presented in the context of the results achieved.
\end{abstract}

Keywords: Children's literatüre, content analysis, master thesis, doctoral thesis 


\section{Giriş}

Bireyin erken çocukluk döneminden itibaren kitapla buluşup haşır neşir olmasının okuma alışkanlığını kazandırmada ilk büyük adım olduğu artık bilinen bir gerçektir. (Pembecioğlu, 2006; Temizkan, 2009; Dehaene, 2014). Toplumun da zamanla bu inanca sahip olması çocukların kitapla karşılaşma yaşını geçmişe oranla düşürmüş, talebe bağlı olarak çocuk kitapları da nicelik ve nitelik açısından çeşitlenmiş, çoğalmıştır.

Çocuğa yönelik kitaplarda çocuk edebiyatının yeri ayrıcalıklıdır. Çünkü çocuk edebiyatı, kurmaca dünyalar yoluyla çocuğun kendini ve dünyayı tanımasını, anlamasını sağlayan, ruhsal gelişimini destekleyen, hayallerine hitap eden, ona insan, eşya ve hayata dair her şeyi farklılık ve çeşitlilikleri ile sunan, onun estetik duygu ve beğenilerini geliştiren bir edebiyattır. Çocuk edebiyatı eserleri; çocuğa, okuduklarını ayrıştırma, süzme, yorumlama, algıladıklarından yeni anlamlar üretme becerilerini kazandırarak iyi bir okur olma yolunda hazırlayıcı roller üstlenir. Tüm bu özellikleri taşıdığı için diğer edebi mecralar kadar özel ve önemlidir.

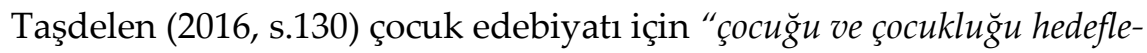
yen bir edebiyat" ifadesini kullanır. Bu ifade çocuk edebiyatının çocuğa göre olanı oluşturmak, ele aldığı herhangi bir konuyu çocuğa göre geliştirmek amacını taşıdığı anlamına gelmesi bakımından önemlidir. Yazarın dış dünyayı algılayıp estetik hale getirirken okur kitlesinin özelliklerini de dikkate alması, farklı bir söyleyişle yazınsal estetiğe zarar vermeden çocuğun gelişim aşamaları konusunda bilgi sahibi olup gerekli hassasiyeti göstermesi beklenir.

Çocuk edebiyatının genel edebiyattan ayrı bir alan olduğunu düşünenler, çocuk edebiyatının geçiş dönemi edebiyatı olduğunu savunanlar, çocuk gerçekliğine dayalı bir çocuk edebiyatının var olduğunu iddia edenler arasında geçmişten günümüze çeşitli tartışmalar yaşanmıştır (Şirin, 2016). $\mathrm{Bu}$ tartışmaların temel kaynağı eserlerin estetik olma, fayda verme veya eğitme kaygılarıyla yaratılmalarında aranabilir. Daha açık ifadeyle çocuk edebiyatı eserinin var oluşunda, çocuğa dair zihinsel, ruhsal, duyusal vasıflar göz önüne alınırken eserin edebilik değer ve ölçütlerden feragat etme endişesi çocuk edebiyatının varlığının kabulünde bahsi geçen bu karşıt görüşlere ortam hazırlamaktadır. Şirin (2007, s.41) edebiyatın var 
olma kıstaslarının çocuk edebiyatı için de geçerli olduğunu belirtirken çocuksu duyarlığın, çocuk gerçekliğinin ve çocuğa görelik özelliklerinin de gerekliliği üzerinde durmaktadır. Ona göre bu kavramlar göz ardı edilirse çocuk ve gençlik edebiyatının kendi bağlamından koparılarak eleştirilip değerlendirilmesine zemin hazırlar. Bu durum ise konu hakkında doğru yargiya varabilmenin önündeki en büyük engel olur.

Puurtinen (1995) de Şirin (2007) gibi duruma 1lımlı ve bütünsel yaklaşarak çocuk edebiyatının edebi ve sosyo-eğitimsel bir sisteme ait olduğunu vurgular. Başka bir deyişle çocuk bu eserlerle eğlenme, yaratıcılık ve estetik zevk gereksinimlerini karşılarken eğitim ve sosyalleşme kaynağına da sahip olur (Akt: Erten, 2011).

Edebiyatın tüm alanlarından farklı olarak çocuk edebiyatının taşıdığı çocuğa görelik filtreleri, onun zaman zaman güdümlü bir edebiyat olarak görülmesine neden olmuştur. Oysa gerçek anlamda çocuk edebiyatı eserlerinde herhangi bir durumu veya düzeni değiştirme kaygısı, barındırdığ 1 ideolojinin altını çizerek yansıtma, okur kitlesine dayatma çabası olmamalıdır. O halde çocuk edebiyatı yazarının çocuğa görelik ilkelerini, çocuk gerçekliğini ve çocuksu duyarlılığı kabullenmesi, alımlaması ve eserlerine yansıtmasının değerli olacağının altı çizilmelidir.

Yaşanan bu kavramsal sorunların çözüme kavuşamamasının en önemli sebebi ülkemizde çocuk edebiyatının öneminin fark edilip tanımının teorik olarak yapılmasına rağmen içerik ve sınırlarının netleştirilememiş ve kaynaklarının tasnif edilememiş olmasıdır. Bu hususta bilimsel çalışmaların işe koşulması bir ihtiyaçtır. Çocuk edebiyatının kavram olarak algilanış biçimi, bu alan dâhilindeki eserlerin incelenme yol ve yöntemlerinde de etkili olduğu iddia edilebilir. Dünyada çocuk edebiyatı üzerine 1950'li yıllarda lisans tezleri ile başlayan çalışmaların karşısında ülkemizde çocuk edebiyatı kavramı 1980'lere kadar lisansüstü çalışmalarda konu olmamıştır (Gürel, 1992' den Akt: Yazıcı, 2013). Bu akademik eksiklik ve gecikmeye çocuk edebiyatının bu zamana kadar önemsenmemesi, ayrı bir alan olarak görülmesi noktasında yaşanan edebî mufazakârlık veya yeniliklere kapalılığın neden olduğu söylenebilir. Zaman içerisinde çocuk edebiyatının değeri fark edilmiş, makale ve bildirilerin yanı sıra lisansüstü çalışmalar da konu etrafında çeşitlenmiştir. Alanyazında yer alan bu çalışmaların seyir ve eğilimlerinin bir bütün olarak değerlendirilmesi çocuk edebiyatının akademik dünyada algılanış biçimini gözler önüne sermek 
açısından önem arz eder. Bu bağlamda ülkemizde çocuk edebiyatı konulu bibliyografya çalışmaları (Göçmen, 1995; Gürel ve Şimşek, 2005; Demircan, 2008; Altunya, 2012) ile çocuk edebiyatı konulu bilimsel çalışmaları değerlendiren araştırmalara rastlanmaktadır (Sınar, 2006; Demircan, 2007; Balc1, 2012 ve Yazıc1, 2013).

\section{Araştırmanın amacı ve önemi}

Bu çalışma 2011'den günümüze kadar yazılmış olan çocuk edebiyatı odaklı yüksek lisans ve doktora tezleri üzerinde ayrıntılı çözümleme yapma, geçmiş incelemeleri devam ettirme, çocuk edebiyatı hakkında yeni yapılacak olan araştırmalara kaynak oluşturma amacındadır. Bu amaç çerçevesinde Türkiye' de çocuk edebiyatı hakkında yapılmış olan lisansüstü çalışmaları yıl, üniversite, enstitü, alan, yazıldığı dil, konu, incelenen tema, konu alınan yazar/şair, hitap edilen dil ve kültür, kullanılan yöntem, veri kaynakları, veri analiz teknikleri açlarından değerlendirilecektir. Değerlendirme aşağıda verilmiş olan araştırma sorularına yanıt arama yoluyla yapılacaktır:

a) Çocuk edebiyatı alanında yapılmış lisansüstü çalışmalarının tanımlayıcı özellikleri nelerdir?

b) Çocuk edebiyatı alanında yapılmış lisansüstü çalışmalarının içerik özellikleri nelerdir?

c) Çocuk edebiyatı alanında yapılmış lisansüstü çalışmalarının metodolojik özellikleri nelerdir?

\section{Yöntem}

\subsection{Araştırma deseni}

$\mathrm{Bu}$ araştırmada, çocuk edebiyatı konusunda yapılmış yüksek lisans ve doktora tezleri içerik analizi ile değerlendirmeye alınmıştır. İçerik analizi, araştırmacının herhangi bir kişi ya da duruma doğrudan dâhil olmadan inceleme yaptığı bir yöntemdir (Bıkmaz, Aksoy, Tatar ve Altınyüzük, 2013). Çalık ve Sözbilir (2014) içerik analizinin parametrelerini irdeledikleri çalışmalarında içerik analizini meta-analiz, meta-sentez ve betimsel içerik analizi olmak üzere üç boyutta açıklamışlardır. Bu araştırmanın ana 
eksenini de bir konu hakkında birbirinden bağımsız çalışmaların ele alınması, çalışma yönelimlerinin ve sonuçlarının açıklayıcı ve tanımlayıcı türden değerlendirmesi içeren betimsel içerik analizi oluşturmaktadır (Çalık ve Sözbilir, 2014)

\subsection{Verilerin toplanmasi}

Bu çalışmaya 2011-2018 yılları arasında çocuk edebiyatı konusunda yapılmış olan 278 lisansüstü çalışma dâhil edilmiştir. Çalışmaların

a) YÖK ulusal tez veri tabanına kayıtlı olmaları,

b) Yüksek lisans ve doktora düzeyinde hazırlanmış olmaları,

c) Roman, öykü, şiir ve benzeri edebi türler, MEB'in belirlemiş olduğu temel eserler, ders kitaplarında yer alan edebi metinler, çocuk kitapları, gençlik edebiyatı üzerine hazırlanmış olmaları,

d) 2011-2018 yılları arasında yapılmış olmaları dikkate alınmıştır.

Konuyla ilgili 2012 yılına kadar hazırlanmış olan tezleri inceleyen benzer çalışmaların varlığı nedeniyle (Demircan, 2007; Balcı, 2012; Yazıcı, 2013) bu konuda tekrara düşmemek ayrıca bahsi geçen çalışmaların süreç bağlamında devamını oluşturmak amacıyla zaman sınırlamasına gidilmiştir.

Üniversitelerde Çocuk Edebiyatı dersi ile ilgili çalışmalar, bu araştırmada hedeflenen amaç bünyesinde olmadığı düşünülerek kapsam dışı bırakılmıştır. YÖK ulusal tez veri tabanında bulunan tezler "çocuk edebiyatı, gençlik edebiyatı, çocuk şiirleri, çocuk romanları, çocuğa görelik, çocuksu duyarlılı" ifadeleri kullanılarak tarama yapılmıştır. Tarama sonucunda yer alan her bir tez başlık, anahtar kelime ve özet okuma yoluyla değerlendirmeye tabi tutulmuş ve araştırmacı tarafından çalışma öncesinde hazırlanmış tez değerlendirme formu kategorilerine göre listelenmiştir. Formun hazırlanması sürecinde Çalık ve Sözbilir (2014) ile Baş ve Sağırlı (2017)'nın çalışmalarından faydalanılmıştır.

\subsection{Kodlama süreci:}

Tez taramasından sonra her çalışmanın kodlaması, değerlendirme for- 
munda yer alan tanımlayıcılık, içerik ve metodoloji ana başlıklarında yapilmiştır.

Tanımlayıcılık kategorisini, tez başlığı, yazar ismi, tezin tamamlandığı yıl, tez türü, tezin sunulduğu üniversite, enstitü, bilim dalı, yazım dili alt başlıkları oluşturmaktadır. Alt başlıklarla ilgili bilgilerin derlenmesinde tez künyelerinde yer alan beyanlar esas alınmıştır.

İçerik kategorisi tez konusu, incelenen tema, ele alınan yazar ve/veya şair, incelenen çocuk edebiyatı ürünlerinin dâhil olduğu dil ve kültür alt başlıklarından ibarettir. İçerik kategorisinin kodlanmasında tezin başlığı, içindekiler bölümü, özeti, anahtar sözcükleri okunmuş, tez konusu ve incelenen tema başlıkları altında her bir tez için en az üç betimleyici anahtar ifade geliştirilmiştir. Bu anahtar ifadeler benzerlikler ve farklılıklar açısından karşılaştırılmış, kendi aralarında gruplandırılarak kodlamalar oluşturulmuştur. Örnek olarak konu alt başlığında kodlama yapılırken, tez başlıklarından ya da özetlerinden yola çıkılarak belirlenmiş olan "eğiticilik, eğitsel, eğitimcilik, eğitme" ifadeleri "eğiticilik/eğitsel ileti" kod başlığı altında toplanmıştır.

Metodoloji kategorisi çalışmanın yöntemi, veri kaynağı ve veri analizi alt başlıklarını yer almaktadır. Kapsama alınan tezlerin neredeyse tamamı araştırmada kullanılan yöntem, veri toplama tekniği ve veri analizi hakkında yeterli bilgi barındırmakta olup iki tezde bu hususta eksiklik görülmüştür. Bu sebeple bu tezler bütün olarak incelenerek yöntem kapsamında kodlaması araştırmacı tarafından yapılmıştır.

Kategorinin aynı alt başlığında iki veya daha fazla veri içeren tezler birden fazla kodlanmıştır. Örnek olarak belgesel tarama ve görüşmenin tercih edildiği tezler veri kaynağı başlı̆̆ında iki kod ile listelenmiştir. İçerik kategorisi alt başlıklarında araştırmacı tarafından yapılan kodların tanımları Türkçe öğretimi alanında uzman bir öğretim üyesi tarafından kontrol edilmiştir. Elde edilen öneri ve görüşler doğrultusunda kodların bazıları birleştirilerek yeniden düzenlenmiştir.

\subsection{Verilerin analizi}

İncelenen tezlerden elde edilen veriler Excel program dosyasına aktarılmış ve analiz edilmiştir. Bulgular frekans/yüzde tabloları ve grafiklerle görselleştirilerek yorumlanmıştır. 


\section{Bulgular}

Bu bölümde araştırma verilerinin analizinden elde edilen bulgulara yer verilmiş, bulgular araştırma sorularının sunuluş sırasıyla aktarılmıştır.

\section{1. Çocuk edebiyatı alanında yapılmış lisansüstü çalışmalarının tanım-} layıcı özelliklerine (yıl, üniversite, enstitü, bilim dalı, yazıldığı dil) ilişkin bulgular

\subsubsection{Tezlerin yıllara göre dağılımı}

Aşağıda çocuk edebiyatı alanında yapılmış lisansüstü çalışmaların yıllara göre dağılımını gösteren Grafik 1 ve açıklamalarına yer almaktadır.

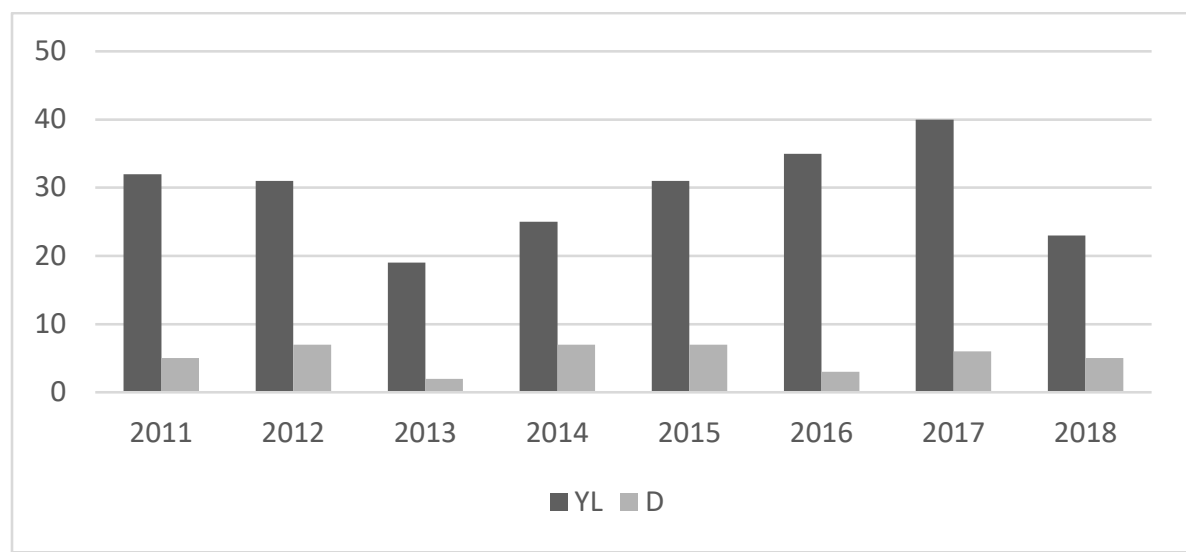

Grafik 1. Çocuk edebiyatı odaklı tezlerin yıllara göre dağılımı

Araştırma verileri ülkemizde 2011 ile 2018 yılları arasında çocuk edebiyatı odaklı 236 yüksek lisans, 42 doktora tezi yapıldığına işaret etmektedir. Grafik 1 incelendiğinde çocuk edebiyatı kapsamında hazırlanmış olan yüksek lisans tez sayılarında yıllar arasında farklılıklar olduğu, bu farlılıkların çok küçük oranda da olsa doktora tezlerinde de görüldüğü söylenebilir. Yüksek lisans düzeyindeki çalışmaların en az 2013 yılında ( $\mathrm{f}=19$ ) en fazla 2017 yılında ( $\mathrm{f}=40)$; doktora düzeyinde çalışmaların en az 2013 yılında ( $\mathrm{f}=2)$, en fazla 2012, 2014, 2015 yıllarında ( $\mathrm{f}=7$ ) olduğunu göstermektedir. 


\subsubsection{Tezlerin üniversitelere göre dağılımı}

Aşağıda çocuk edebiyatı alanında yapılmış lisansüstü çalışmaların üniversitelere göre dağılımını gösteren Tablo 1 ve açıklamaları yer almaktadir.

Tablo 1. Çocuk edebiyatı odaklı tezlerin üniversitelere göre dağılımı

\begin{tabular}{|c|c|c|c|c|c|}
\hline Üniversite & $f$ & Üniversite & $f$ & Üniversite & $f$ \\
\hline Ankara Ü & 32 & Haliç Ü & 4 & Süleyman Demirel Ü & 2 \\
\hline Atatürk Ü & 17 & İnönü Ü & 4 & Yaşar Ü & 2 \\
\hline Hacettepe Ü & 15 & Selçuk Ü & 4 & Yeditepe Ü & 2 \\
\hline Afyon Kocatepe $\ddot{U}$ & 13 & Uludağ Ü & 4 & Adnan Menderes Ü & 1 \\
\hline Yüzüncü Y Yl Ü & 13 & Yıldız Teknik Ü & 4 & Akdeniz Ü & 1 \\
\hline $\begin{array}{l}\text { Çanakkale Onsekiz } \\
\text { Mart Ü }\end{array}$ & 12 & Ege Ü & 3 & Anadolu Ü & 1 \\
\hline Gazi Ü & 12 & Erzincan Ü & 3 & Atılım $\ddot{U}$ & 1 \\
\hline Marmara Ü & 8 & Fatih Ü & 3 & Dumlupinar Ü & 1 \\
\hline Dokuz Eylül Ü & 7 & Muğla Sttk1 Koçman Ü & 3 & Kadir Has Ü & 1 \\
\hline İstanbul Ü & 7 & Trakya Ü & 3 & Kafkas Ü & 1 \\
\hline Mersin Ü & 7 & Adiyaman Ü & 2 & Kırklareli Ü & 1 \\
\hline Abant İzzet Baysal Ü & 6 & Ahi Evran Ü & 2 & Kilis 7 Aralık Ü & 1 \\
\hline Balıkesir Ü & 6 & Başkent Ü & 2 & Kocaeli Ü & 1 \\
\hline Çukurova Ü & 6 & Bingöl Ü & 2 & Mehmet Akif Ersoy Ü & 1 \\
\hline Firat Ü & 6 & Bülent Ecevit Ü & 2 & Hacı Bektaş Veli Ü & 1 \\
\hline Gaziantep Ü & 6 & Celal Bayar Ü & 2 & Okan $\ddot{U}$ & 1 \\
\hline Necmettin Erbakan Ü & 6 & Erciyes $\ddot{U}$ & 2 & Ordu Ü & 1 \\
\hline Ondokuz Mayıs Ü & 5 & Eskişehir Osmangazi Ü & 2 & Pamukkale Ü & 1 \\
\hline Sakarya Ü & 5 & İstanbul Arel Ü & 2 & Recep Tayyip Erdoğan Ü & 1 \\
\hline Uşak Ü & 5 & İstanbul Aydın Ü & 2 & Siirt Ü & 1 \\
\hline Fatih Sultan Mehmet Ü & 4 & Orta Doğu Teknik Ü & 2 & & \\
\hline
\end{tabular}

Tablo 1, 2011-2018 yılları arasında çocuk edebiyatı odaklı lisansüstü çalışmaların toplam 62 üniversitede yapıldı̆̆ını göstermektedir. Tezlerin en fazla sırasıyla Ankara Üniversitesi ( $\mathrm{f}=32$ ), Atatürk Üniversitesi ( $\mathrm{f}=17)$, Hacettepe Üniversitesi, ( $\mathrm{f}=15)$, Afyon Kocatepe Üniversitesi ( $\mathrm{f}=13)$, Yüzüncü Y1l Üniversitesi'nde $(\mathrm{f}=13)$ hazırlandığ 1 da görülmektedir.

\subsubsection{Tezlerin enstitülere göre dağılımı}

Aşağıda çocuk edebiyatı alanında yapılmış lisansüstü çalışmaların enstitülere göre dağılımını gösteren Tablo 2 ve açıklamaları yer almaktadır 
Tablo 2. Çocuk edebiyatı odaklı tezlerin enstitülere göre dă̆ılımı

\begin{tabular}{llll}
\hline Enstitüler & $Y L$ & $D$ & Toplam \\
\hline Eğitim Bilimleri Enstitüsü & 105 & 25 & 140 \\
Sosyal Bilimler Enstitüsü & 120 & 17 & 137 \\
Sağlık Bilimleri Enstitüsü & 4 & - & 4 \\
Yaşayan Diller Enstitüsü & 4 & - & 4 \\
Atatürk İlkeleri ve İnkılap Tarihi Enstitüsü & 1 & - & 1 \\
Enformatik Enstitüsü & 1 & - & 1 \\
Medeniyetler İttifakı Enstitüsü & 1 & - & 1 \\
\hline
\end{tabular}

Tablo 2 incelendiğinde tezlerin en fazla Eğitim Bilimleri enstitülerinde ( $\mathrm{f}=140$ ) yapıldığı onu Sosyal Bilimler enstitülerinin ( $\mathrm{f}=137$ ) takip ettiği görülmektedir. Yüksek lisans tezlerinin ağırlıklı olarak Sosyal Bilimler enstitülerinde ( $\mathrm{f}=120)$ hazırlandığı, doktora tezlerinde ise Eğitim Bilimleri enstitülerinin ( $\mathrm{f}=25$ ) Sosyal Bilimler enstitülerinden ( $\mathrm{f}=17$ ) önde olduğu anlaşılmaktadır. Konuyla ilgili diğer yüksek lisans tezleri Sağlık Bilimleri $(\mathrm{f}=4)$, Yaşayan Diller $(\mathrm{f}=4)$, Atatürk İlkeleri ve İnkılap Tarihi $(\mathrm{f}=1)$, Enformatik ( $\mathrm{f}=1$ ) ve Medeniyetler İttifakı enstitülerinde $(\mathrm{f}=1)$ dağılım göstermiş olup bahsi geçen enstitülerde araştırma amacı kapsamında doktora tezi yapılmamıştır.

\subsubsection{Tezlerin bilim dalına göre dağılımı}

Aşağıda çocuk edebiyatı alanında yapılmış lisansüstü çalışmaların bilim dalına göre dağılımını gösteren Tablo 3 ve açıklamaları yer almaktadır

Tablo 3. Çocuk edebiyatı odaklı tezlerin bilim dalına göre dağılımı

\begin{tabular}{llllll}
\hline Bilim dalı & YL & D & Bilim dalı & YL & D \\
\hline Türkçe Eğitimi & 110 & 21 & Yabancı Diller Eğitimi & 2 & 2 \\
Türk Dili ve Edebiyatı & 21 & 4 & Atatürk İlkeleri ve İnkılap Tar. & 1 & - \\
Okul Öncesi Eğitimi/Öğrt. & 10 & 1 & Balkan Çalışmaları & 1 & - \\
Mütercimlik Tercümanlık & 8 & - & Bilişsel Bilim & 1 & - \\
Grafik Tasarımı & 7 & - & Doğu Dilleri ve Edebiyatları & 1 & 1 \\
Alman Dili ve Ed./Eğitimi & 6 & 2 & Eğitim Prog. ve Öğretim & 1 & - \\
Güzel Sanatlar Eğitimi & 6 & 3 & Eğitimin Sos. ve Tar. Temelleri & 1 & - \\
Sınıf Eğitimi & 6 & - & Ekonometri & 1 & - \\
Çocuk Gelişimi ve Eğitimi & 5 & 1 & Fars Dili ve Edebiyatı & 1 & - \\
İlköğretim & 5 & - & Gazetecilik & 1 & 1 \\
Temel İslam Bilimleri & 5 & - & İşletme & 1 & -
\end{tabular}




\begin{tabular}{llllll} 
İngiliz Dili ve Ed./Eğitimi & 4 & - & Medeniyet Araştırmaları & 1 & - \\
Kürt Dili ve Edebiyatı & 4 & - & Örgütsel Davranış & 1 & - \\
Temel Eğitim & 4 & - & Özel Eğitim & 1 & - \\
Türk Dili ve Ed. Eğt. & 4 & - & Sosyoloji & 1 & - \\
Batı Dilleri ve Edebiyatı & 4 & 2 & Yakınçă̆ Tarihi & 1 & - \\
Sosyal Bilgiler Eğitimi & 3 & - & Yeni Medya & 1 & - \\
Çağdaş Türk Lehçeleri ve Ed. & 2 & - & Türk Dünyası Edebiyatları & - & 1 \\
Karşılaştırmalı Edebiyat & 2 & - & Türk Dünyası Araştırmaları & - & 1 \\
Sanat ve Tasarım & 2 & - & Felsefe ve Din Bilimleri & - & 2 \\
\hline
\end{tabular}

Tablo 3'e bakıldığında homojen olmasa da çocuk edebiyatı odaklı tezlerin çeşitli alanlarda hazırlanmış olduğu görülür. En fazla tez çalışmasının yapıldığı bilim dalı olan Türkçe Eğitimi'ni (YL f=110; D f=21) Türk Dili ve Edebiyatı (YL f=21; D f=4), Okul Öncesi Eğitimi/Öğrt. (YL f=10, D f=1), Mütercimlik Tercümanlık (YL f=8) ve Grafik Tasarım (YL f=7) bilim dallarının takip ettiği görülür. Genel anlamda çocuk edebiyatıyla ilgili yüksek lisans yapma sıklığı doktora tezine göre yüksektir. Türkçe Eğitimi ile diğer bilim dalları arasında hem yüksek lisans hem doktora düzeyi çalışmalar açısından büyük bir fark olduğu Tablo 3'e bakarak söylenebilir.

\subsubsection{Tezlerin yazıldığı dile göre dağılımı}

Aşağıda çocuk edebiyatı alanında yapılmış lisansüstü çalışmaların yazıldıkları dile göre dağılımını gösteren Grafik 2 ve açıklamaları yer almaktadir.

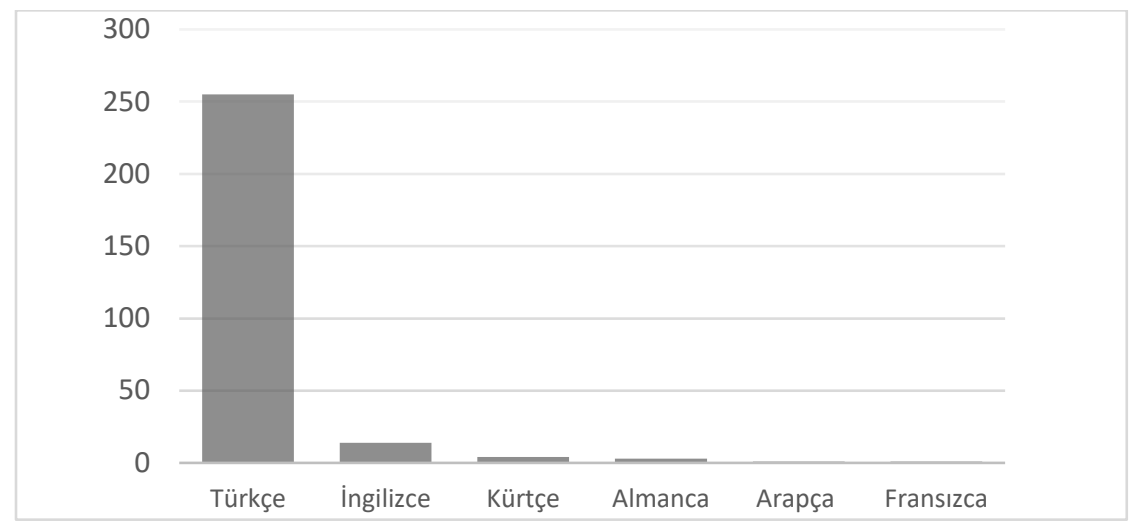

Grafik 2. Çocuk edebiyatı odaklı tezlerin yazıldıkları dillere göre dağılımı 
Grafik 2 tezlerin büyük oranının Türkçe ( $\mathrm{f}=255)$ yazıldığını, 14 tez ile İngilizcenin ikinci sırada olduğunu yansıtmaktadır. Tezlerin yazıldığı diğer dillerin sırasıyla Kürtçe ( $f=4)$, Almanca $(f=3)$, Arapça ( $f=1$ ) ve Fransızca $(\mathrm{f}=1)$ olduğu bulgusu da Grafik 2' de yer almaktadır.

3.2. Çocuk edebiyatı alanında yapılmış lisansüstü çalışmalarının içerik özelliklerine (Konu, incelenen tema, yazar/şair/çocuk edebiyatçlları, dil ve kültür) ilişkin bulgular

\subsubsection{Tezlerin konulara göre dağılımı}

Aşağıda çocuk edebiyatı alanında yapılmış lisansüstü çalışmaların konulara göre dağılımını gösteren Grafik 3 ve açıklamaları yer almaktadır.

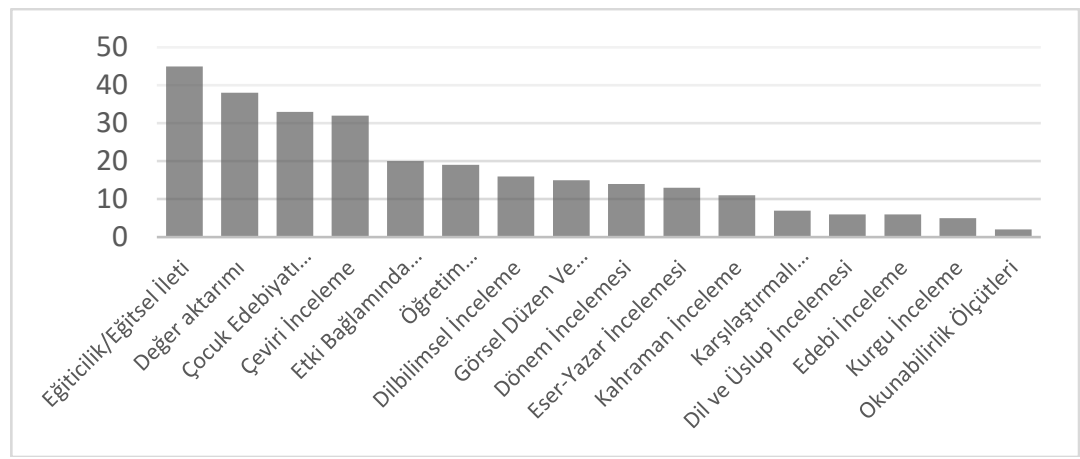

Grafik 3. Çocuk edebiyatı odaklı tezlerin konulara göre dağılımı

Tezlerin odaklandığı konular 16 kategori altında gruplandırılmış ve sıklık değerleri Grafik 3'e yansıtılmıştır. Odak noktası çocuk edebiyatı olan tezlerin konularının ağırlıklı olarak eğiticilik/eğitsel ileti $(\mathrm{f}=45)$ değer aktarımı ( $\mathrm{f}=38)$, çocuk edebiyatı ölçütleri ( $\mathrm{f}=33$ ) ve çeviri inceleme ( $\mathrm{f}=32$ ) olduğu görülmektedir. En az çalışılan konuların ise karşılaştırmalı inceleme ( $\mathrm{f}=7$ ), dil ve üslup incelemesi $(\mathrm{f}=6)$ edebi inceleme ( $\mathrm{f}=6)$, kurgu inceleme ( $\mathrm{f}=5$ ) ve okunabilirlik ölçütleri $(\mathrm{f}=2)$ değerlendirmesi olduğu ifade edilebilir. 


\subsubsection{Tezlerde incelenen temalar}

Çocuk edebiyatı alanında yapılmış lisansüstü çalışmalarda incelenen temaların dağılımını gösteren Tablo 4 ve açıklamaları aşağıda yer almaktadir.

Tablo 4. Çocuk edebiyatı odaklı tezlerde incelenen temalar

\begin{tabular}{llll}
\hline İncelenen temalar & $f$ & İncelenen temalar & $f$ \\
\hline Çocuk & 9 & Atatürk & 1 \\
\hline Eğitim & 9 & Barış & 1 \\
\hline Toplumsal cinsiyet & 6 & Başarı güdüsü & 1 \\
\hline Kültür/kültürel öge & 6 & Coğrafi kavramlar & 1 \\
\hline Din/dini öge & 5 & Demokrasi bilinci & 1 \\
\hline Karakter gelişimi & 4 & Folklor & 1 \\
\hline Dil ve kavram gelişimi & 4 & Göç/Göçmenlik & 1 \\
\hline Büyülü Gerçekçilik & 3 & Korku/Şiddet & 1 \\
\hline Fantastik & 3 & Kötülük & 1 \\
\hline İmgeler & 3 & Mizah unsuru & 1 \\
\hline İnsan hakları & 3 & Oryantalizm & 1 \\
\hline Sosyal yaşam & 3 & Ölüm & 1 \\
\hline Cumhuriyet & 2 & Sağlı & 1 \\
\hline Çevre bilinci & 2 & Siyaset & 1 \\
\hline Empati & 2 & Türk aydınlanması & 1 \\
\hline Aile & 1 & Türk kimliği & 1 \\
\hline
\end{tabular}

Araştırma kapsamına alınan tezlerin bir bölümü çocuk edebiyatı eserlerini çeşitli temalar bağlamında incelemeye odaklanmıştır. Tezlerde 32 farklı tema tespit edilmiştir. Tablo 4'te inceleme açısından tercih edilen temalar sunulmuş olup ilk beşinin çocuk $(\mathrm{f}=9)$, eğitim $(\mathrm{f}=9)$, toplumsal cinsiyet $(\mathrm{f}=6)$, kültür/kültürel öge $(\mathrm{f}=6)$, din/dini öge $(\mathrm{f}=5)$ temaları olduğu görülmektedir.

\subsubsection{Tezlerde incelenen yazar ve şairler}

Aşağıda çocuk edebiyatı alanında yapılmış lisansüstü çalışmalara biyografileri ve/veya eserleri dâhil edilen yazar ve şairleri içeren Tablo 5 ve açıklamaları yer almaktadır. 
Tablo 5. Çocuk edebiyatı odaklı tezlerde kapsama alınan yazar ve şairler

\begin{tabular}{llllll}
\hline Yazar/şair & $f$ & Yazar/şair & $f$ & Yazar/şair & $f$ \\
\hline Gülten Dayığlu & 5 & Abdullah Ziya Kozanoğlu & 1 & J.K. Rowling & 1 \\
Mustafa Ruhi Şirin & 5 & Adnan Özyalçıner & 1 & Jonathan Swift & 1 \\
Aytül Akal & 4 & Ahmet Ümit & 1 & Jules Verne & 1 \\
Mevlâna İdris Zengin & 4 & Ahmet Yılmaz Boyunağa & 1 & Kâmil Keylânî & 1 \\
Yalvaç Ural & 4 & Ali Nazima & 1 & Kemalettin Tuğcu & 1 \\
Gülsüm Cengiz & 3 & Ali Ekrem Bolayır & 1 & Koray Avcı Çakman & 1 \\
Muzaffer İzgü & 3 & Angela Carter & 1 & Manastırlı Mehmet Rıfat & 1 \\
Nur İçözü & 3 & Aydoğan Yavaşlı & 1 & Mark Twain & 1 \\
Rıfat Ilgaz & 3 & Ayla Kutlu & 1 & Marlen Haushofer & 1 \\
Yavuz Bahadıroğlu & 3 & Aysel Gürmen & 1 & Mehmet Güler & 1 \\
Ayla Çınaroğlu & 2 & Ayşe Yamaç & 1 & Michel Ende & 1 \\
Bestami Yazgan & 2 & Behiç Ak & 1 & Mikayıl Müşfik & 1 \\
Bilgin Adalı & 2 & Bican Veysel Yıldız & 1 & Miyase Sertbarut & 1 \\
Cahit Zarifoğlu & 2 & Comtesse de Segur & 1 & Mustafa Balel & 1 \\
Erich Kästner & 2 & Çetin Öner & 1 & Numan Kartaş & 1 \\
Fatih Erdoğan & 2 & Daniel Handler & 1 & Ömer Seyfettin & 1 \\
Fazıl Hüsnü Dağlarca & 2 & Deniz Erbulak & 1 & Özlem Aytek & 1 \\
Hasan Kallimci & 2 & Eleanor H. Porter & 1 & Rakım Çalapala & 1 \\
İpek Ongun & 2 & Feridun Oral & 1 & Reşat Ekrem Koçu & 1 \\
Mavisel Yener & 2 & Gianni Rodari & 1 & Rıfat Özdek & 1 \\
Memduh Şevket Esen- & 2 & Gülnar Kandeyer & 1 & Sara Gürbüz Özeren & 1 \\
dal & & & & & \\
Necdet Neydim & 2 & Hasan Latif Sarıyüce & 1 & Sevinç Kuşoğlu & 1 \\
Samed Behrengi & 2 & Heinrich Böll & 1 & Seza Kutlar Aksoy & 1 \\
Sevim Ak & 2 & Hidayet Karakuş & 1 & Sulayman Rıspayev & 1 \\
Talip Apaydın & 2 & Howard Pyle & 1 & Süleyman Bulut & 1 \\
Zeynep Cemali & 2 & İsmet Kür & 1 & Üzeyir Gündüz & 1 \\
& & & & Vahap Akbaş & 1 \\
\hline
\end{tabular}

Türk çocuk edebiyatı kapsamında eserleri incelemeye konu olan ilk beş yazarın Gülten Dayığlu (f=5), Mustafa Ruhi Şirin (f=5), Aytül Akal (f=4) Mevlâna İdris Zengin ( $\mathrm{f}=4$ ) ve Yalvaç Ural $(\mathrm{f}=4)$ olduğu Tablo 5 'te görülmektedir. Yabancı çocuk edebiyatı kapsamında ise Erich Kästner ( $\mathrm{f}=2)$ ve Samed Behrengi'nin ( $\mathrm{f}=2$ ) eserleri diğerlerinden fazla inceleme konusu olmuştur. 


\subsubsection{Tez içeriklerinin dil ve kültür bağlamında dağılımı}

Aşağıda çocuk edebiyatı alanında yapılmış lisansüstü çalışma içeriklerinin dil ve kültüre göre dağılımını gösteren Grafik 4 ve açıklamaları yer almaktadır.

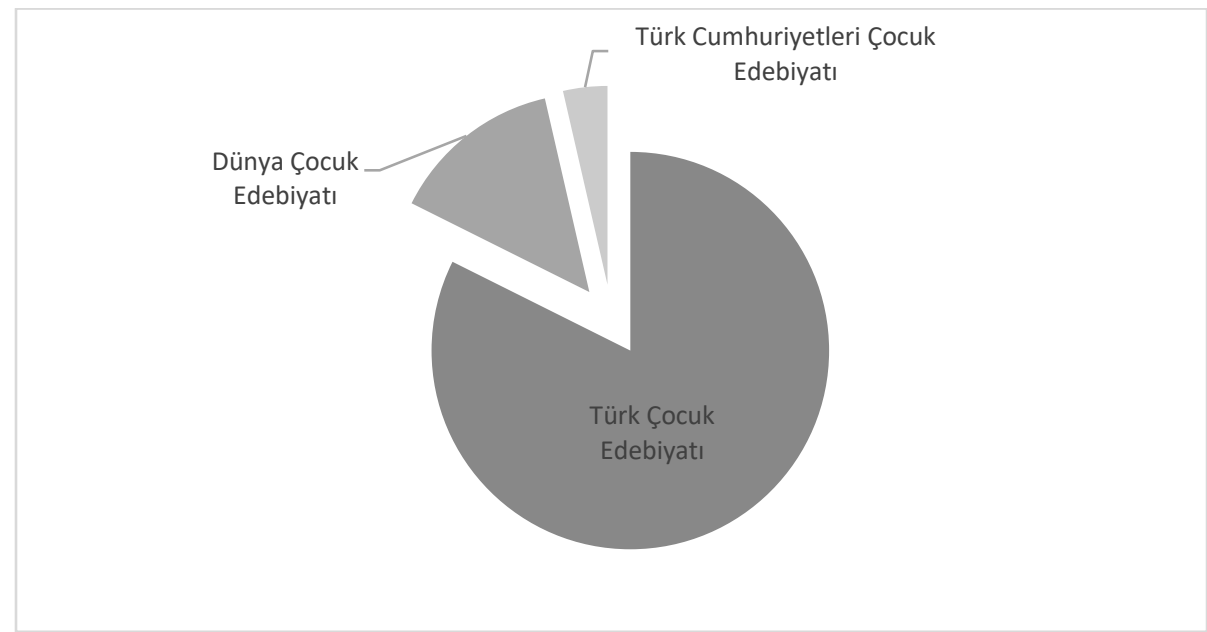

Grafik 4. Çocuk edebiyatı odaklı tez içeriklerinin dil ve kültüre göre dağılımı

Grafik 4, çalışmaların \%82'si Türk çocuk edebiyatı ( $\mathrm{f}=229)$ üzerine olmasının yanı sıra \%14 oranında dünya çocuk edebiyatı ( $\mathrm{f}=39$ ) ve $\% 4$ oranında diğer Türk cumhuriyetleri çocuk edebiyatı $(\mathrm{f}=10)$ üzerine de hazırlandığını göstermektedir.

3.3. Çocuk edebiyatı alanında yapılmış lisansüstü çalışmaların metodolojik (Yöntem, veri kaynakları, veri analizi) özelliklerine ilişkin bulgular

\subsubsection{Tezlerin yöntemlere göre dağılımı}

Aşağıda çocuk edebiyatı alanında yapılmış lisansüstü çalışmaların yöntemlerine göre dağılımını gösteren Grafik 5 ve açıklamaları yer almaktadir. 


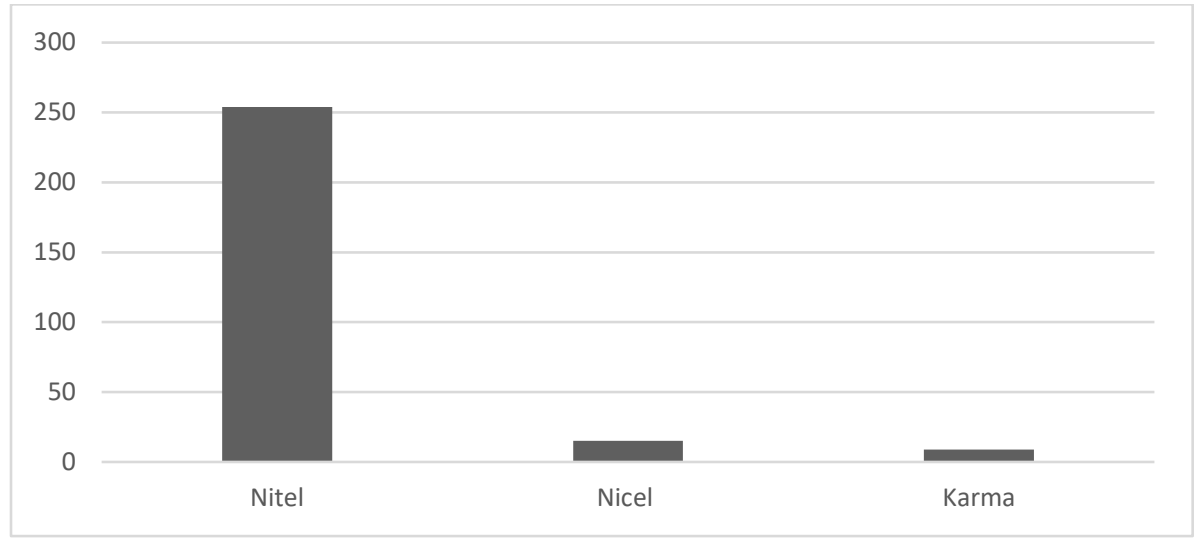

Grafik 5. Çocuk edebiyatı odaklı tezlerin yöntemlere göre dă̆ılımı

Grafik 5 incelendiğinde, tezlerin \%91.33 oranında nitel çalışma yöntemini ( $\mathrm{f}=254$ ) benimsedikleri, onu \%5,41 oranıla nicel çalışma yöntemini $(\mathrm{f}=15)$, \%3,24 oraniyla karma yöntemi ( $\mathrm{f}=9)$ takip ettiği görülmektedir.

\subsubsection{Tezlerin kullanılan veri kaynaklarına göre dağılımı}

Aşağıda çocuk edebiyatı alanında yapılmış lisansüstü çalışmaların kullanılan veri kaynaklarına göre dağılımını gösteren Grafik 6 ve açıklamaları yer almaktadır.

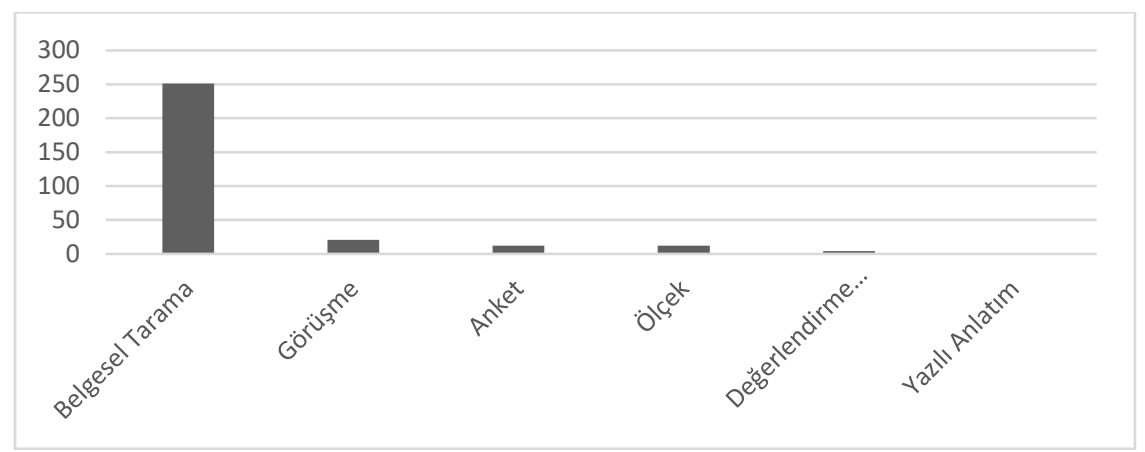

Grafik 6. Çocuk edebiyatı odaklı tezlerin veri kaynaklarına göre dağılımı

İncelenmiş olan tezlerin bir kısmında tek veri kaynağından bir bölümünde ise birden fazla veri kaynağından yararlanılmıştır. Grafik 6 veri 
kaynakları olarak \%83,38'lik oranda belgesel tarama ( $\mathrm{f}=251), \% 6,97^{\prime} \operatorname{sinin}$ görüşme ( $\mathrm{f}=21), \% 3,98^{\prime}$ inin anket $(\mathrm{f}=12)$ ve ölçek ( $\left.\mathrm{f}=12\right), \% 1$,33' ünün değerlendirme envanteri $(\mathrm{f}=4)$ ve $\% 0,33$ 'ünün yazılı anlatım değerlendirmesinin $(\mathrm{f}=1)$ tercih edildiğini gösterir.

\subsubsection{Tezlerin kullanılan veri analiz tekniklerine göre dağılımı}

Aşağıda çocuk edebiyatı alanında yapılmış lisansüstü çalışmaların kullanılan veri analiz tekniklerine göre dağılımını gösteren Grafik 7 ve açıklamaları yer almaktadır

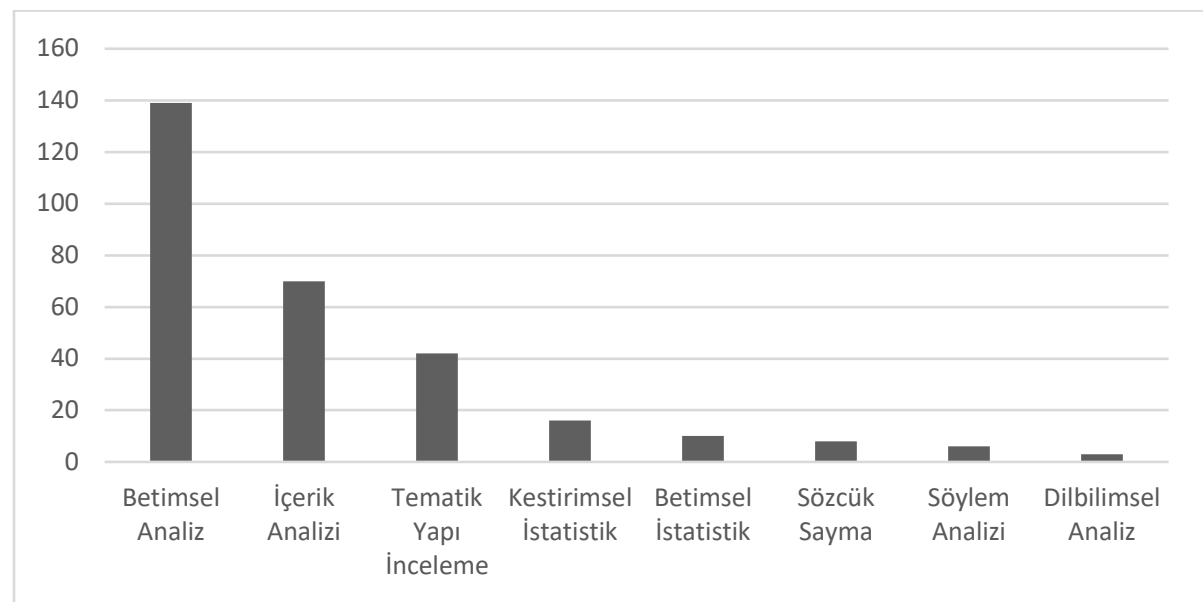

Grafik 7. Çocuk edebiyatı odaklı tezlerin veri analiz tekniklerine göre dağılımı

Grafik 7'de tezlerde kullanılmış olan veri analiz tekniklerini göstermekte olup en sık tercih edilen ilk üç tekniğin \% 47,27 oranla betimsel analiz ( $\mathrm{f}=139), \% 23,80$ oranla içerik analizi $(\mathrm{f}=70)$ ve $\% 14,28^{\prime}$ lik oranla tematik yapı inceleme ( $\mathrm{f}=42)$ olduğu görülmektedir. Çalışmaların \% 2,72'sinin nitel veri analiz tekniklerinden sözcük sayma ( $\mathrm{f}=8), \% 2,04$ 'ünün söylem analizi ( $\mathrm{f}=6), \% 1,02$ ' sinin dilbilimsel analiz ( $\mathrm{f}=3$ ), nicel veri analiz tekniklerinde ise çalışmaların \%5,44'ünün kestirimsel istatistik ( $\mathrm{f}=16$ ), \% 3,4'ünün betimsel istatistik ( $\mathrm{f}=10)$ kullandığı Grafik 7'ye yansımıştır. 


\section{Sonuç ve Öneriler}

Çocuk edebiyatı odaklı yüksek lisans ve doktora tezleri tanımlayıcılık, içerik ve metodolojik özellikleri açılarından incelenmiş olup ulaşılan sonuç ve öneriler bu bölümde sunulmuştur.

\subsection{Sonuç}

Araştırma sonucunda 2011-2018 yılları arasında çocuk edebiyatı konulu 278 lisansüstü tezin hazırlandığ 1 tespit edilmiştir. Ulaşılan bu sayı önceki çalışmalarla karşılaştırıldığında çocuk edebiyatını tez konusu olarak tercih etme eğiliminin zaman içerisinde arttığı söylenebilir (Demircan, 2007; Yazıc1, 2013). Yüksek lisans tez sayısının dört yıllık süre içinde (2013-2017) iki katına çıktığı, 2018 yılı itibarıyla oldukça gerilediği; doktora düzeyinde iki çalışma ile en az tezin 2013 yılında yazıldığı, bu sayının 2012, 2014 ve 2015 yıllarında en fazla yediye yükseldiği tespit edilmiştir.

Araştırma bulgularına göre konuyla ilgili en fazla çalışmanın tamamlandığı ilk üç üniversite sırasıyla Ankara, Atatürk ve Hacettepe üniversiteleridir. Bu sonuca benzer olarak, 1981-2012 yılları arasında hazırlanmış tezleri inceleyen Yazıcı (2013) makalesinde, diğer üniversitelere göre Ankara Üniversitesi'nde daha fazla sayıda çocuk edebiyatı odaklı lisansüstü çalışma yapıldığını ifade etmiştir.

Çocuk edebiyatı odaklı yüksek lisans ve doktora tezlerinin en sık eğitim bilimleri enstitülerinde yapıldığı, onu ikinci sırada sosyal bilimler enstitülerinin takip ettiği belirlenmiştir. Bu bulgu, daha önceki çalışmalarda yer alan eğitim bilimleri enstitülerine oranla sosyal bilimler enstitülerinde daha fazla sayıda tez kayıtlı olduğu sonucundan farklıdır (Balc1, 2012; Yazıc1, 2013). Buna göre son yıllarda enstitüler arasındaki farkın yüksek lisans düzeyinde kapandığı, diğer enstitülere nazaran eğitim bilimlerinde daha fazla sayıda çocuk edebiyatı konulu doktora tezi hazırlandığı belirtilebilir. Eğitim bilimleri enstitülerinin artması, kapsadığı bölümlerin çeşitlenmesi, çocuk edebiyatının eğitsel anlamda değerinin fark edilmesi ile disiplinler arası çalışmaların gittikçe önem kazanması bu sonucun nedenleri olarak gösterilebilir. 
Çocuk edebiyatı eserleri sadece metinsel düzeyde değil, onu oluşturan unsurlar ile bir bütün olarak incelenmelidir (Erten, 2011). Araştırma kapsamına alınan tezlerde de bu bağlamda çoklu değerlendirmeler mevcuttur. Çalışma bulguları, seçilen konuların ağırlıklı olarak eğiticilik, eğitsel ileti, değer aktarımı, çocuk edebiyatı ölçütleri ve çeviri inceleme olduğuna işaret etmektedir. Bunun aksine dil ve üslup incelemesi, edebi inceleme, karşılaştırmalı eser incelemesi, kurgu incelemesi ve okunabilirlik ölçüt değerlendirmesi konularında daha az sayıda tez hazırlandığı ortaya çıkmıştır. Bu sonuç, ülkemizde çocuk edebiyatı çalışmalarında 'çocuğa göre, çocuğa uygun' bir eser ortaya koymanın eğiticilik, öğreticilik kanalından geçtiği anlayışının var olduğunu vurgulaması bakımından oldukça önemlidir. Bir anlamda çocuk edebiyatı incelemelerinde de öğretme kaygısının edebîlik kavramını oluşturan unsurları gölgelediği söylenebilir.

Balcı (2012) makalesinde 1981-2010 yılları arasında çocuk edebiyatı alanında hazırlanan lisansüstü çalışmalarda en çok edebi tür incelemeleri, çocuk eğitimi ve çocuk edebiyatı, çocuk edebiyatı yazarları, çocuk gazete ve dergileri, görsel unsurlar ve resimleme konularının tercih edildiğini ifade eder. Şu durumda her iki çalışma sonucunun birbirinden farklı olduğu, zamanla çocuk edebiyatı eserlerini eğitsellik açısından değerlendirmeye rağbet edildiği yargısına varılabilir. Ülkemizde, incelenmiş olan tezler sınırlılı̆̆ında, çocuk edebiyatı eserlerini edebi çözümleme yöntemleri yoluyla değerlendirmede yetersiz kalındığını söylemek mümkündür. Web of Science veri tabanına kayıtlı 1558 makaleyi inceleyen Haba-Osca ve ark. (2018) bu makalelerin ağırlık olarak edebiyat $(\% 32,16)$, eğitim/eğitim araştırmaları $(\% 15,88)$ ve dil/dilbilim $(\% 6,99)$ konularında yapıldığını belirlemişlerdir. Haba-Osca ve ark. (2018)'ın ulaşmış olduğu çocuk edebiyatı araştırmalarında edebi incelemelerin eğitsel değerlendirmelerden iki kat fazla olduğu sonucuyla bu araştırma bulguları çelişmektedir. Eğer ülkemizde çocuk edebiyatı dairesindeki metinlerin çift kodlu ve çok sesli yap1ları fark edilip önemsenirse (Can, 2014) çocuk edebiyatı eserlerinin edebi kuram ve eleştiri bağlamında akademik çalışmalara konu edilmeye değer olduğu savunu ve çabasının artacağı öngörülebilir.

Türk çocuk edebiyatının oluşum ve gelişiminde çevirinin yeri önemli ve özeldir (Karadağ, 2018). Bu araştırma kapsamında derlenen tezlerde en çok tercih edilen konulardan birinin çeviri metinler olması, farklı dil ve 
kültüre ait çocuk edebiyatı eserlerinin Türk çocuk edebiyatı ile etkileşimini ortaya koyması bakımından dikkate değerdir.

Lisansüstü çalışmalarda genellikle eserlerin tematik yapılarının çözümlenmesinde veya eserleri yapılandıran unsurların tespit edilmesinde belli temalardan yola çıkılmıştır. Bunlardan "çocuk, eğitim, toplumsal cinsiyet, kültürel ve dini unsurlar" ağırlıklı olmak üzere toplam 32 farklı tema tanımlanmıştır.

Çocuk edebiyatı ile ilgili konular sıklıkla Türkçe eğitimi bilim dalında çalışılmıştır. Türkçe derslerinde yararlanılacak metin kaynaklarının genellikle çocuk edebiyatı alanından sağlanması ile Türkçe öğretmenlerinin öğrencilere okuma alışkanlığını kazandırırken onların kitaplarla haşır neşir olmalarında üstlendiği sorumluluk da Türkçe eğitimi bölümlerinin çocuk edebiyatı konusunu diğer bilim dallarına nazaran daha fazla sahiplenmesinin nedenleri olabilir.

Tezlerde yazım dili olarak Türkçeden sonra en sık İngilizce kullanılmıştır. Demircan (2007)'ın çalışması ile karşılaştırıldığında son yıllarda İngilizce yazımın arttığı, Almanca yazımın belirgin oranda azaldığı, yazım dillerinde az da olsa çeşitlenme olduğu belirlenmiştir.

Tezlerin büyük oranda Türk çocuk edebiyatı üzerine hazırlanmış olmasının yanı sıra dünya çocuk edebiyatı ve diğer Türk cumhuriyetleri kapsamındaki çocuk edebiyatı eserleri üzerine de yazılmış tezlerin varlığından bahsedilebilir. Çalışmalarda en sık Gülten Dayığlu ve Mustafa Ruhi Şirin'in eserlerinin değerlendirildiği sonucuna ulaşılmış olup bu bulgu Yazıcı (2013)'nın ulaştığı sonuçla benzerlik gösterir. Tezlerde yabancı çocuk edebiyatı kapsamında ise en sık Erich Kästner ve Samed Behrengi'nin eserleri ele alınmıştır.

Çocuk edebiyatı, kaynağı metin olan bir saha olduğundan konuyla ilgili akademik çalışmalarda büyük oranda nitel yöntemlerin tercih edilmesi öngörülen bir sonuçtur. Ayrıca daha önceki çalışma bulgularına kıyasla nicel ve karma yöntemlerin giderek arttığı görülür. Çocuk edebiyatı üzerine farklı disiplinlerin eğilmiş olması araştırma yöntemlerinde farkl1laşmayı beraberinde getirir. Yöntem çeşitliliğinin küçük oranda artışı, veri kaynakları ve analizindeki yelpazeyi de az da olsa genişletmiştir. Bu araştırmalarda en sık betimsel analizden yararlanıldığı bunun yanı sıra içerik analizi gibi daha derin ve detaylı çözümlemeler yaparak sonuçlara ulaşma yoluna gidildiği de tespit edilmiştir. 
Çalışma sonuçlarını kısaca toparlamak gerekirse; Türkiye'de çocuk edebiyatının öneminin zaman içerisinde fark edildiği, buna rağmen eserlerin çok anlamlılığını ortaya çıkarmak yerine tematik yapıyı betimleme yoluna gidildiği, çocuğa yönelik eser incelemelerinde eğitsellik ve değer aktarımı kapsamındaki konulara ağırlık verildiği ayrıca dünya çocuk edebiyatının nitelikli örneklerinin ülkemizde yaygın olarak tercih edilip okunduğu göz önüne alındığında karşılaştırmalı incelemelerin yeterli düzeyde olmadığı söylenebilir.

\section{2. Öneriler}

Çocuk edebiyatı eseri yaratılırken okurun estetik zevk ve beğenilerine hitap etmekten ziyade, dayalı olduğu mantıksal yapının ön plana çıkarılması, onun edebilik değerini zayıflatmakla kalmayacak yazarı sınırland1rarak onun hareket alanını daraltma, çocuğu didaktik veyapay eserler ile karşılaştırma gibi riskleri artıracaktır. Bunların önüne geçebilmek için çocuk edebiyatının çocuğa yönelik her eseri kapsamadığı anlayışının tam anlamıyla yerleşmesi yerinde olacaktır. Ayrıca ulaşılan sonuçlar bağlamında gelecek araştırmalar için farklı edebi metin inceleme yöntemleriyle çocuk edebiyatı eserlerinin çözümlenmesi, Türk ve dünya çocuk edebiyatı eserlerinin karşılaştırmalı olarak incelenip değerlendirilmesi önerilebilir.

Çocuk edebiyatı üzerine yapılan akademik çalışmalarda yöntem çeşitliliğinin artırılması özellikle karma yöntemle planlanmış çalışmaların daha sık uygulanması, bu edebiyatın kuramsal gelişimine katkıda bulunmakla birlikte çocuğa yönelik eserlerin eğitim-öğretim ortamında göstereceği etkinin sınanması açısından da değerli olacaktır. Akademik incelemelerin çeşitli yönlerden çocuk edebiyatının seyrine etki ettiği düşünüldüğünde, yazarlar kadar çocuk edebiyatı alanı uzmanlarının da çocuk edebiyatı noktasında sorumluluk üstlenmesi gereği ifade edilebilir. 
EXTENDED ABSTRACT

\section{A Content Analysis Post-Graduate Studies in Turkey About Children's Literature (2011-2018 Period) \\ *}

Elif Emine Balta

Freelance Researcher

As a first big step in gaining reading habit, the fact that an individual meet with books appropriate to her/him from early childhood and mingles with them is a known fact anymore. The place of children's literature is privileged in terms of books appropriate for children. It is a kind of literature that enables child to recognize and understand himself and world through the fictional worlds and support his/her spiritual development and that catch his/her fancy and offers to him/her all sorts of differences about human beings, things and life and that takes into consideration the aesthetic feelings and tastes of the child besides all these. The works of children's literature play a preparatory role for child to be a good reader by providing the child with the skills of parsing, filtering, interpreting what he/she reads and producing new meanings from what he/she perceive. As it has all these features, it is as special and important as other literary channels.

The perceiving of a concept is effective in its analysis and assessing as well. The concept of children's literature in Turkey had not been the subject of postgraduate studies until the 1980s (Gürel, 1992'den Akt: Yazıcl, 2013). For this reason, even if the definition of children's literature had been made and its importance had been recognized, its framework had not been determined and its resources could not be classified. The articles and papers in this direction as well as postgraduate studies have been prepared after the 1980s. The assessing the tendencies of these academic studies in the literature as a whole is crucial in terms of perceiving how the children's literature is perceived in the academic world. This study aims to make detailed analysis regarding the master's and doctoral thesis on children's literature, which has been written since 2011 up to day and con- 
tinue the reviews, and to create resource for the researches about children's literature. The answers were sought for the following problems in the frame of this aim:

a) What are the defining characteristics of postgraduate studies that have been done on children's literature?

b) What are the content characteristics of postgraduate studies that have been done on children's literature?

c) What are the methodological characteristics of postgraduate studies that have been done on children's literature?

\section{Method}

The master's and doctoral theses that have been done on children's literature were evaluated with content analysis in this research. Content analysis is a method by which the researcher investigates subject without getting directly involved in any person or situation (Bıkmaz, Aksoy, Tatar ve Altınyüzük, 2013).

Theses found in the national thesis database of the Council of Higher Education were searched by using the statements of "children's literature, youth literature, child's poetry, childish susceptibility". Each thesis was evaluated by the title, keyword and of abstract reading and listed by the researcher in accordance with the thesis evaluation form categories prepared before the study. It was made benefit of Çalık \& Sözbilir (2014) and Baş \& Sağırlı (2017)'s studies were utilized during the process of preparing the form. After the thesis review, the coding of each study was performed under the titles of the descriptiveness, content and methodology.

\section{Results}

As a result of the research, it was determined that 278 postgraduate thesis on children's literature was done between the years of 2011 and 2018 (Demircan, 2007; Yazıc1, 2013). When this number attained is compared with previous studies, it can be stated that the tendency to choose children's literature as a thesis topic has increased over time. There has been an increase in the number of master's and doctoral theses on children's literature in institute of educational sciences in recent years. The increase in the 
number of institute of educational sciences, the diversifying of the departments it covers and the increasing importance of interdisciplinary studies by being recognized the value of children's literature in educational terms can be stated as the reasons of this result.

The findings of the study indicate that the subjects selected have been mainly the instructiveness, educational message, value transfer children's literature criteria, and translation review. On the contrary, a smaller number of theses revealed to have been prepared in the subjects of the language and style study, literary review, comparative work review, fiction review, and readability criterion evaluation. This result shows that there is an understanding for the fact that composing the work "appropriate to child" in children literature in our country be possible by means of trainings and teaching channels. It was determined that postgraduate studies usually focus on the analysis of thematic structures in the works. Out of these, a total of 32 different themes were identified, including child, education, gender, and cultural and religious elements.

To sum up the results of the study briefly; it can be stated that the importance of children's literature in Turkey is recognized in time and that description of thematic structure is preferred instead of revealing the polysemy of the works though, and that is focused on subjects in the scope of educational and value transfer. In addition, when considering that the high quality samples of world children's literature are widely preferred and read in our country, it can be said that comparative studies are not sufficient.

While composing a work regarding children's literature, the emphasis on the logical structure to which it is based rather than addressing the aesthetic tastes and acclaim of the reader, will weaken its literal value and expose the child to the didactic and artificial works. It would be appropriate to imbed the understanding that children's literature does not cover every work regarding the child in order to prevent these problems. Analyzing children's literature and giving importance to comparative studies can be suggested for future research. Considering the fact that academic reviews affect the course of children's literature in various aspects, it can be stated that the children's literature experts as well as the writers should need to take responsibility in the subject of children's literature. 


\section{Kaynakça / References}

Altunya, H. (2012). Türk çocuk edebiyatı kaynakçası. Ankara Üniversitesi Çocuk ve Gençlik Edebiyatı Uygulama ve Araştırma Merkezi.

Balcı, A. (2012). Türkiye'de çocuk edebiyatı üzerine hazırlanan lisansüstü tezler hakkında bir meta-analiz çalı̧̧ması. Mustafa Kemal Ü Sosyal Bilimler Enstitüsü Dergisi, 9(17), 195-206.

Baş, F. ve Sağırlı, M. Ö. (2017). Türkiye'de eğitim alanında üstbiliş odaklı yapılan makalelere yönelik bir içerik analizi. Eğitim ve Bilim, 42(192).

Bıkmaz, F. H., Aksoy, E., Tatar, Ö., ve Altınyüzük, C. A. (2013). Eğitim programları ve öğretim alanında yapılan doktora tezlerine ait içerik çözümlemesi (1974-2009). Ĕ̆itim ve Bilim, 38(168).

Can, D.T. (2014). Çocuk edebiyatı: Kuramsal yaklaşım. Konya: Eğitim Kitabevi.

Çalık, M. ve Sözbilir, M. (2014). İçerik analizinin parametreleri. Ĕ̆itim ve Bilim, 39(174).

Dehaene, S. (2014). Beyin nasıl okur? Okumanın bilimi ve evrimi. (Çev. O. Karakaş). İstanbul: Alfa Bilim.

Demircan, C (2007). Çocuk edebiyatı konulu lisansüstü çalışmalar ile ilgili bir durum araştırması. Sakarya Üniversitesi Eğitim Fakültesi Dergisi, 13, 23-35.

Demircan, C. (2008). Çocuk edebiyatına yönelik bir bibliyografya denemesi (1960-1980). Pamukkale Üniversitesi Sosyal Bilimler Enstitüsü Dergisi, (1), 165-187.

Erten, A. (2011). Çocuk yazını çevirisine yaklaşımlar. Ankara: Hacettepe Yayincilik.

Göçmen, A. (1995). Çocuk edebiyatı makaleler bibliyografyası (1953-1991). Ege Üniversitesi, Edebiyat Fakültesi Yayımlanmamış Lisans Tezi, İzmir.

Gürel, Z. ve Şimşek, T. (2005). Çocuk edebiyatı üzerine bir bibliyografya denemesi. Hece Dergisi Çocuk Edebiyatı Özel Sayısı, 104-105.

Haba-Osca, J., Ambròs, A., ve Osca-Lluch, J. (2018). Scientific production in children's literature through the Web of Science. Language Teaching and Educational Research, 1(1), 78-93. 
Karadağ, A. B. (2018). Çeviri çocuk edebiyatı bağlamında asimetrik güç ilişkileri: Yetişkin çevirmenler ve çocuk okurlar. S. Taş (Ed.), Çeviribilimde güncel tartışmalardan kavramsal sorgulamalara, içinde: (ss. 43-77) İstanbul: Hiperlink.

Pembecioğu, N. (2006). İletişim ve çocuk. Ankara: Ebabil.

Sınar, A. (2006). Türkiye' de çocuk edebiyatı çalışmaları. Türkiye Araştırmaları Literatür Dergisi, 4(7), 175-225.

Şirin, M. R. (2007). Çocuk edebiyatı kültürü. Ankara: Kök Yayıncılık.

Şirin, M. R. (2016). Edebiyat ve çocuk edebiyatı edebiyatın amacı ve işlevi. Türk Dili Dergisi. CX (780), 12-31.

Temizkan, M. (2009). Metin türlerine göre okuma eğitimi. Ankara: Nobel Yayın Dağıtım.

Yazıcı, N. (2013). Çocuk edebiyatı alanında üniversitelerde yapılan lisans sonrası çalışmalar. Hacettepe Üniversitesi Eğitim Fakültesi Dergisi, 28(1), 441-452.

\section{Kaynakça Bilgisi / Citation Information}

Balta, E. E. (2019). Çocuk edebiyatı üzerine yapılmış lisansüstü çalışmaların içerik analizi (2011-2018 yılları). OPUS-Uluslararası Toplum Araştırmaları Dergisi , 10(17), 464-489. DOI: 10.26466/ opus.510809 